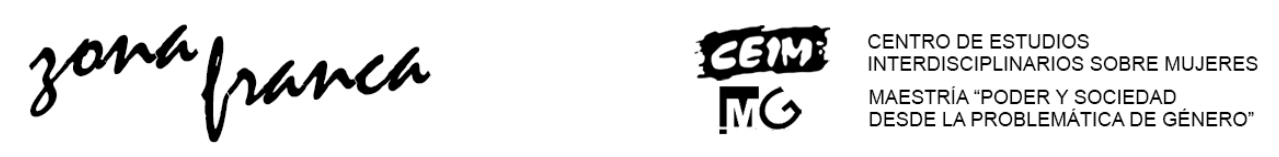

\title{
El feminismo y sus olas
}

Eli Bartra*

“Un predador se vuelve más peligroso cuando está herido". Noam Chomsky'

\section{Resumen}

En este texto se exponen una serie de reflexiones sobre los principales debates que se han dado en el seno del pensamiento feminista de los últimos años. No están todos, desde luego, sino que se eligieron justamente los más polémicos alrededor de los cuales no existe un consenso. En tanto activista por varias décadas he podido pensar lo que planteo desde adentro y en tanto académica me permito una mirada relativamente distante, con la necesaria distancia como para poder ver mejor algunas cuestiones.

Palabras clave: feminismo - diversidad - patriarcado -
esencialismo - acoso

\section{Feminism and its Waves}

\section{Abstract}

In this text I reflect on the main debates within recent feminist thought. I do not offer a general panorama, but instead focus upon those that are the most polemic, and about which a consensus does not exist. As an activist for many decades I offer some ideas from inside that experience. However, as an academic

* Profesora Distinguida Universidad Autónoma Metropolitana-Xochimilco. Doctora en Filosofía, UNAM, Maestría en Estética, París V, Sorbonne. Contacto: ebartra@correo.xoc.uam.mx

' Este artículo de Noam Chomsky, "A predator becomes more dangerous when wounded" fue publicado en The Guardian el 9007. https://www.globalpolicy.org/component/content/article/156/26387.html consultada 20 octubre 2020.

Revista Zona Franca- Centro de estudios interdisciplinario sobre las mujeres (CEIM)- Maestría poder y sociedad desde la problemática de género (MG), Rosario, Argentina. ISSN, 2545-6504 http://zonafranca.unr.edu.ar/index.php/ZonaFrancal Número 28 (2020). 
my view is somewhat more removed, and takes the necessary distance to be able to see some things more clearly.

\section{Key words: feminism - diversity - patriarchy - essentialism - harassment}

Reflexiones en voz alta, personales y colectivas al mismo tiempo, de lo que me ha dado la participación en el activismo feminista, así como de la escucha de múltiples pensares es lo que ofrezco aquí, en el otoño de mi vida, y desde el confinamiento por el covid-19 primero en el Mediterráneo, mismo mar que baña el Orán de Albert Camus en su estremecedora novela La peste escrita en 1947, y también desde un lacerado México.

\section{Singular y plural}

Recientemente las feministas de lengua castellana se han puesto a expresar numerosas cuestiones nodales sobre feminismo. Finalmente, parece que las ideas fluyen. Es algo relativamente nuevo pues no se habían escrito tantos textos llamémosle teóricos, filosóficos o simplemente reflexivos, en tan poco tiempo, sobre el significado de las luchas feministas y sobre las ideas, los conceptos y las categorías que lo acompañan. Debe tener que ver con el hecho de que el propio movimiento está viviendo (o estaba antes de la pandemia, aunque parece que sigue de todas maneras) un periodo de efervescencia muy significativo.

El feminismo en singular incomoda más que los feminismos. De la misma manera que hablar de la mujer (en singular) es rechazado por un buen número de feministas de Occidente supuestamente antiesencialistas. Incluso hablar de mujeres no gusta mucho, pero si se dice género es más amable, es pasable. $\mathrm{Y}$, desde luego, la famosa y desafortunada "perspectiva de género" se lleva las palmas. El feminismo ha sido el fantasma número uno (quizá más que el comunismo) que ha recorrido el mundo por siglos. Es un fantasma porque por más que lo han querido asir, atrapar, se escurre y reaparece después de un tiempo en

Revista Zona Franca- Centro de estudios interdisciplinario sobre las mujeres (CEIM)- Maestría poder y sociedad desde la problemática de género (MG), Rosario, Argentina. ISSN, 2545-6504 http://zonafranca.unr.edu.ar/index.php/ZonaFranca| Número 28 (2020). 
el mismo o en otro lugar, con una apariencia distinta. El feminismo es este poderoso movimiento de las mujeres contra la opresión de género, contra la dominación de los hombres hacia las mujeres, al que algunos hombres se han unido, en efecto, desde siempre. Pero es de mujeres porque somos las primeras interesadas en que desaparezca la desigualdad, la violencia sistemática y sistémica, la marginación, la invisibilización... porque el patriarcado no se ha ido, aún se encuentra reinando.

Muchas han sido y son las explicaciones sobre los orígenes del patriarcado y de la subordinación femenina. Muchas también las hipótesis. De la misma manera que diversas han sido y son las estrategias y las luchas que se llevan a cabo contra el dominio patriarcal. De ahí que se piense que existen varios feminismos. De ahí que, en realidad, son muchas las formas que va cobrando la conceptualización, la forma de nombrar un proceso, de abordarlo y de atacarlo. Por eso se piensa que hay muchos feminismos. Y, sobre todo, porque desde el interior del propio feminismo surgieron voces de mujeres negras, en particular, que empezaron (y continúan) hablando de un feminismo hegemónico, racista, excluyente y que ha marginado a lesbianas, negras, indígenas, discapacitadas... Todo ello es más que certero. Voces supuestamente feministas en todo el mundo han llevado a cabo marginaciones y exclusiones, deliberadas o no, y más, pero no creo que se trate de un feminismo hegemónico. Nunca ha habido un feminismo hegemónico. También se ha hecho referencia en diversas publicaciones a lo largo de los años a un feminismo blanco que mantiene el statu quo. Aparte de que la noción peca de racista es equívoca pues si defiende el estado de cosas actual no es feminismo, es un quehacer patriarcal y neoliberal."

Siempre ha habido un movimiento amplio, plural y diverso integrado por una enorme cantidad de distintos grupos y tendencias con ideas diferentes. $Y$ no como piensa Luna Follegati que el movimiento feminista empezó a ser plural en el siglo

"Ver, por ejemplo, el texto de Alejandra Pretel https://afrofeminas.com/2020/06/02/a-que-nosreferimos-cuando-hablamos-de-feminismo-blanco/ consultada 5 de agosto 2020.

Revista Zona Franca- Centro de estudios interdisciplinario sobre las mujeres (CEIM)- Maestría poder y sociedad desde la problemática de género (MG), Rosario, Argentina. ISSN, 2545-6504 http://zonafranca.unr.edu.ar/index.php/ZonaFrancal Número 28 (2020). 
XXI (2017: 271).Por ejemplo, en México las mujeres del Partido Comunista Mexicano que integraban la Unión Nacional de Mujeres Mexicanas se salieron del recién creado Frente Nacional por la Liberación y los Derechos de las Mujeres (FNALIDM) en 1979, porque no estaban de acuerdo en que hubiera lesbianas participando, ni que se las apoyara en sus movilizaciones (Lau Jaiven, 2014).Pero ellas nunca fueron feminismo hegemónico ni nada parecido.

Creo que hay un problema recurrente que ha enfrentado y sigue enfrentando el movimiento feminista y que considero muy grave. Puesto que todas (y todos) nos hemos formado y estructurado políticamente, dentro de supuestas democracias representativas, con las ideas de los partidos políticos y de la política por representación de la ciudadanía, se piensa con frecuencia que dentro del feminismo se tiene también que representar a las personas. Ese es un error monumental. Muchas mujeres dicen que no se sienten REPRESENTADAS por el feminismo. Y bueno quizá eso es porque no se han metido y han levantado su voz y sus demandas específicas dentro de él. Lo afirma todavía en el presente alguien como Frances Ryan: "Pero como mujer discapacitada durante mi infancia en el Reino Unido a principios de los 90, no me sentí representada por el feminismo tal como se presentaba a mi generación."'I"En los años 70, hace medio siglo, ya me sorprendió enormemente cuando en una reunión del movimiento una compañera lesbiana me dijo que porque no decía yo algo con respecto a las lesbianas. Mi respuesta fue que era ella quien tenía que decirlo y no yo. Yo no me representaba más que a mi misma, por lo tanto, si su interés era que se considerara colectivamente, que se abordara la problemática lésbica, era ella quien lo tenía que plantear. No era un sistema de representaciones y no lo es hoy en día. De ahí que cada mujer, desde sus identidades plantea de la manera que le parece mejor, en grupos de mujeres de diferentes edades o bien en grupos solo de jóvenes o en grupos solo de viejas. En colectivas de distintas etnias mezcladas o en grupos solo de indígenas o solo de negras. Pero cada quien lo tiene que proponer,

III "Butas a disabled woman growing up in the UK in the early 90's, I didn't feel represented by feminism as it was being presented to my generation." (2018, pp. 77-78).

Revista Zona Franca- Centro de estudios interdisciplinario sobre las mujeres (CEIM)- Maestría poder y sociedad desde la problemática de género (MG), Rosario, Argentina. ISSN, 2545-6504 http://zonafranca.unr.edu.ar/index.php/ZonaFranca| Número 28 (2020). 
aportar, nadie debería decirlo por las otras nadie debería de representar a las discapacitadas. Ellas mismas son quienes deben hablar por ellas. Pero pienso que eso no se ha entendido todavía. (El caso de la discapacidad mental es diferente pues diferente es su situación y, a menudo, requieren -ahí sí- de personas que las apoyen, representen).

Tenemos también el hecho de que la National Organization for Women (NOW) de los Estados Unidos en 1969, al parecer, dijo que las lesbianas eran una amenaza para el feminismo (Eric-Udorie 2018: XVII). Se trató de uno de los primeros grupos, liberal este, con un feminismo tibio y excluyente, como dice June Eric-Udorie, pero tampoco fue hegemónico y dominante. Por la sencilla razón de que este no ha existido. La misma autora también afirma que "Desde la época de Sojourner Truth en adelante, las feministas de todas las edades y tipos han ignorado o activamente excluido a los grupos marginalizados." (Ibid). ${ }^{\mathrm{IV}}$ ¿Esta gran diversidad de grupos ha conformado EL feminismo hegemónico excluyente?

Ahora bien, es ya un tópico y una falacia afirmar que las mujeres siempre están unas contra otras, son rivales y se pelean todo el tiempo. No es posible la unidad entre las mujeres por todo ello, son todas diferentes y de ahí, en parte, el problema de la unidad. Incluso llegamos a escuchar una voz como la de Deborah Cameron (2019: 12) que afirma que "como las mujeres son un grupo muy grande, internamente diverso, siempre ha sido difícil unirlas.” ¿Es esto privativo de las mujeres? ¿No sería igualmente aplicable a los varones? La historia de la humanidad ha estado dominada por guerras, interminables, reiterativas, y no han sido las mujeres quienes han ido a guerrear. Que las mujeres compiten por los varones, pues seguramente; de la misma manera que los hombres compiten y se matan por las mujeres. Si las mujeres no se han podido unir nunca ¿cómo es que se produce un feminismo hegemónico?

IV “From Sojourner Truth's day on, feminists of all ages and types ignored or actively excluded marginalized groups."

Revista Zona Franca- Centro de estudios interdisciplinario sobre las mujeres (CEIM)- Maestría poder y sociedad desde la problemática de género (MG), Rosario, Argentina. ISSN, 2545-6504 http://zonafranca.unr.edu.ar/index.php/ZonaFranca| Número 28 (2020). 
El feminismo ha sido internacionalista, global. Es sabido que las mujeres de todo el mundo están sujetas al patriarcado, pero nunca de la misma manera. Jamás se ha pensado que todas las mujeres, de todo el mundo son igualmente dominadas, maltratadas, subordinadas, explotadas, oprimidas. Se ha explicado una y muchas veces las diferencias entre las distintas mujeres en virtud de su etnia, su racialización, su edad, su clase social, su sexualidad o su identidad genérica. En todo caso no es posible pensar hoy que las mujeres de todo el mundo son iguales y oprimidas de la misma manera, pero sí se puede afirmar, como se hizo desde hace muchas décadas, que todas las mujeres del mundo viven en sociedades patriarcales $\mathrm{y}$, por lo tanto, todas viven en condiciones desiguales y desvalorizadas con respecto a los varones. Ello implica el sinnúmero de vejaciones, violencias, discriminaciones, infamias que viven. Nunca ha dicho el neofeminismo que las mujeres conforman un grupo homogéneo e indiferenciado globalmente, esto es, que no diferencia entre las mujeres. Se le ha achacado esta afirmación, pero yo no la he visto escrita en ningún lado. Se le han atribuido toda suerte de ideas, que el feminismo jamás ha expresado. Esa es una más de las tantas estrategias para asustar a propias y extrañas, crear nociones aberrantes para poderlo atacar con "conocimiento de causa" y sin ninguna prudencia.

El movimiento feminista ha servido y sigue sirviendo para mover conciencias. Tanto desde el activismo callejero, como en los medios, tanto en las prácticas artísticas como en la academia sirve para eso, para despertar conciencias. Lo que cada quien logre hacer individual y colectivamente con la conciencia alerta, con el saber de la desigualdad que somete, es otro asunto.

Independientemente de si se adopta el singular o el plural, lo deseable es que haya consistencia en su utilización. Si se postula en un texto o en una conferencia pública que es preciso hablar de los feminismos porque son muchos y diversos, no se puede inmediatamente después decir "el feminismo" es esto o aquello. Evidentemente que no se trata de algo rígido. Se puede pensar que existe un solo feminismo y de repente hablar de los feminismos si así conviene, si es

Revista Zona Franca- Centro de estudios interdisciplinario sobre las mujeres (CEIM)- Maestría poder y sociedad desde la problemática de género (MG), Rosario, Argentina. ISSN, 2545-6504 http://zonafranca.unr.edu.ar/index.php/ZonaFranca| Número 28 (2020). 
acorde con el discurso que se está elaborando. O al revés. Pero con una cierta coherencia teórica.

Por otro lado, si se dice violencia de género, así como estudios de género, son nociones deslavadas para que pasen mejor. Si se habla de mujeres golpeadas o de estudios feministas es muy incómodo, ya se sabe. Pero pienso que no hay que instalarnos en la comodidad de esas nociones, hay que llamar a las cosas por su nombre aunque incomode.

\section{Las olas del movimiento feminista}

No me ha acabado de gustar nunca la periodización de las olas con respecto al movimiento feminista. De ahí que a la llamada 2ª ola la bauticé como neofeminismo en un texto en inglés de 2001. Me sigue pareciendo una noción acertada para el feminismo que inicia en el mundo en la década de 1960 y en México en la de 1970. El problema es la denominación a partir de entonces.

Hemos estado en el entendido de que el movimiento sufragista, la larga lucha por el voto y la educación para las mujeres, es decir, una lucha política en la arena pública, había conformado la $1^{\underline{a}}$ ola del feminismo en el mundo. Ese periodo abarca, grosso modo, desde mediados del siglo XIX hasta que se va obteniendo el derecho al sufragio en los distintos países. Sin embargo, voces muy diversas, pero aisladas, por los derechos de las mujeres, se escucharon en varias partes del mundo, desde mucho antes. Un punto de partida clave fue el trabajo de la francesa Olympe de Gouges (1791) y su muerte en la guillotina en 1793 a los 45 años. Pero en tanto movimiento, como conjunto de mujeres organizadas con metas comunes, no fue sino un siglo después, en el XIX. Ahora bien, por ejemplo, la española Nuria Varela propone una periodización diferente y divide esa primera etapa $u$ ola en dos. Para ella la $1^{\underline{a}}$ ola es la previa al sufragismo del XIX y la $2^{\underline{a}}$ ola es la lucha, propiamente dicha, por el voto y la educación hasta entrado el siglo $X X$. Y a la que se le denominado hasta ahora $2^{a}$ ola, para ella sería la $3^{a}$. Con lo

Revista Zona Franca- Centro de estudios interdisciplinario sobre las mujeres (CEIM)- Maestría poder y sociedad desde la problemática de género (MG), Rosario, Argentina. ISSN, 2545-6504 http://zonafranca.unr.edu.ar/index.php/ZonaFrancal Número 28 (2020). 
cual afirma que "el 8 de marzo de 2018 fue el momento de inflexión de esta cuarta ola" (Varela 2019:27-33; 144). Desde luego, ella se está refiriendo a Europa.

Después de la obtención del voto vino un remanso, en todas partes, una calma, que precedió al surgimiento del neofeminismo (2 $2^{\underline{a}}$ ola) en la década de 1960 en los Estados Unidos. Ahora bien, ha pasado ya medio siglo y no se ha sabido del todo cómo periodizarlo. Eso proviene también del propio hecho de que se trata de olas y no de periodos o eras o épocas. La primera ola (según cómo se periodice) duró mucho más de cincuenta años en algunas partes del mundo y dentro de ella se expresaron muy distintas ideas desde las más radicales (como las de Emma Goldman en los Estados Unidos) hasta las reformistas liberales (quizá como Emmeline Pankhurst en el Reino Unidos). En México los extremos podrían ser desde Hermila Galindo hasta Rosario Castellanos.

El neofeminismo representa ruptura y continuidad al mismo tiempo. Rompe con lo anterior en la medida en que se trató de una lucha fundamentalmente centrada en la toma de conciencia (personal y colectiva) y cuyo interés fue el cuerpo a diferencia de la $1^{\underline{a}}$ ola en la que el cuerpo de las mujeres no era el núcleo de la atención sino principalmente asuntos de ciudadanía. En el neofeminismo se toma conciencia de la subordinación de las mujeres, del patriarcado, de la imposibilidad de decidir sobre nuestros cuerpos, de la violencia contra las mujeres con sus mil rostros.

En tanto movimiento social fue fundamentalmente de clase media que pronto consideró la necesidad de volcarse hacia otras clases sociales. De ahí el intento de alianzas con sindicatos y partidos políticos y, ya en plena década de los 80 , se tornó en un feminismo con aspiraciones de ser popular.

Se dice ahora a menudo que la $3^{\text {a }}$ ola inicia en los 90 del siglo pasado y que ya estamos en la $4^{a}$ que no se sabe del todo cuándo inicia, es posible que en la segunda década del nuevo siglo XXI. Qué es lo que realmente amerita el paso a

Revista Zona Franca- Centro de estudios interdisciplinario sobre las mujeres (CEIM)- Maestría poder y sociedad desde la problemática de género (MG), Rosario, Argentina. ISSN, 2545-6504 http://zonafranca.unr.edu.ar/index.php/ZonaFranca| Número 28 (2020). 
una nueva ola, no está del todo claro tampoco, a excepción del cambio generacional. ¿Cómo y quién decide la periodización y con base en qué?

En México entre la primera y la segunda olas se ve claramente una ruptura significativa, un cambio muy importante. En la primera se lucha hacia afuera, hacia la política formal, hacia lo público: el sufragio y el derecho a la educación. Las batallas se libran en el ágora. En la segunda la lucha está centrada en el cuerpo de las mujeres, como dije: aborto, violación y mujeres golpeadas. Es desde ahí que se salta a lo público, a lo político, pero el activismo es más que nada hacia adentro (en la conciencia) con base en los pequeños grupos. Las manifestaciones en la calle son pobres y a veces francamente insignificantes a pesar de que se hacía mucho ruido. En la década de 1990 hay una vuelta a priorizar la política pública y se acentúa la fragmentación. Es aquí cuando resulta necesario pluralizarlo todo: las mujeres, los feminismos, los géneros. No cabe ninguna duda de que la diversidad se ha manifestado a lo largo de estos 50 últimos años en distintas formas de pensar y luchar, pero el acento se ha puesto en cuestiones específicas, en los 70 se priorizó el cuerpo, en los 80 , los sectores populares y sus necesidades, en los 90, la conquista de los espacios políticos y académicos. En el nuevo milenio el principal interés se encuentra en subrayar las diferencias y hay una vuelta al cuerpo. Ello significaría que en los 80 inicia una nueva ola, en los 90 otra y así cada década. Yo no veo realmente una ruptura significativa a lo largo de 40 años. Hoy sería tal vez ya posible hablar de una $3^{\text {a }}$ ola del feminismo en el mundo en virtud de ciertos cambios que se están llevando a cabo bastante significativos. La mundialización del feminismo, de la mano de la globalización, la masificación, la utilización de las nuevas tecnologías, la permeabilidad de las ideas hacia arriba (los poderes) y hacia abajo (sectores populares) de la sociedad, las redes sociales y el cambio generacional nos hablan de grandes transformaciones. Lo preocupante es que sigue habiendo una continuidad en algunos de los temas de la "agenda", cosa que no sucedía entre la $1^{\mathrm{a}}$ y la $2^{\mathrm{a}}$ ola. Se habían cumplido las metas: se obtuvo el derecho al sufragio y a la educación

Revista Zona Franca- Centro de estudios interdisciplinario sobre las mujeres (CEIM)- Maestría poder y sociedad desde la problemática de género (MG), Rosario, Argentina. ISSN, 2545-6504 http://zonafranca.unr.edu.ar/index.php/ZonaFranca| Número 28 (2020). 
incluso a la superior. En cambio hoy en muchas partes se sigue luchando por la despenalización del aborto, se sigue luchando contra la violación y la violencia hacia las mujeres (que no de género) que se ha acrecentado hasta proporciones inimaginables.

De acuerdo con Deborah Cameron estábamos en 2019 en la $4^{a}$ ola. Sin embargo, no dice concretamente de cuándo a cuándo duró la $3^{2}$ ola. (2019).

Se dice que la historia, la memoria, resultan importantes para el andar en el mundo. Se ha dicho que al conocer el pasado evitamos la repetición de errores, pero también es un lugar común afirmar que nadie aprende en cabeza ajena y que el pasado (en este caso del feminismo) no sirve para las nuevas generaciones. Todas las personitas tropezamos varias veces con la misma piedra. Es probable que eso sea cierto, pero también creo que hay que insistir en que las nuevas generaciones de feministas se asomen un poco al pasado, que lo traten de entender, que lean libros y no solamente notas de internet, y construyan lo que tengan que construir con lo viejo y con lo nuevo. Estoy convencida de que no es positivo que se invente el hilo negro todos los días, para ello pienso que hay que informarse a fondo, conocer lo que se ha dicho y hecho en la historia del feminismo y abrevar del pensamiento feminista existente en el mundo que ya cuenta con un acervo monumental. El trabajo ahora es discernir lo que nos sirve y lo que no.

¿1 $1^{\mathrm{a}}$ ola, $2^{\mathrm{a}}$ ola, $3^{\mathrm{a}}$ ola $4^{\mathrm{a}}$ ola? En virtud de qué, cuál es el cambio o la ruptura que amerite periodizarlo así. Tal vez se trate de una suerte de contraofensiva por parte del patriarcado (en boca de feministas o pseudo-feministas) de atomizar al movimiento lo más posible, de romper la continuidad. Varios grupos de feministas de la diversidad (étnica, sexual, genérica) han intentado por todos los medios borrar el denominador común de opresión entre todas las mujeres y quizá esta es una forma más. Consideran que el denominador común es esencialista.

Revista Zona Franca- Centro de estudios interdisciplinario sobre las mujeres (CEIM)- Maestría poder y sociedad desde la problemática de género (MG), Rosario, Argentina. ISSN, 2545-6504 http://zonafranca.unr.edu.ar/index.php/ZonaFranca| Número 28 (2020). 
En los últimos años nos la hemos pasado definiendo y redefiniendo conceptos y categorías una y otra vez, lo cual es muy bueno. Al llegar la posmodernidad todo se volvió posmo: posfeminismo o postfeminismo, posgénero. poscolonial, poscolonialidad. $Y$ de ahí hemos ido pasando a lo descolonial y decolonial. Desafortunadamente aún no hay claridad sobre muchos de estos conceptos y se utilizan de manera muy laxa y hasta, a menudo, confusa.

Hemos llegado al momento en que si no hacemos referencia en plural -casi con respecto a todo- está perfectamente mal, somos viejas, con un lenguaje obsoleto y ello significa, sobre todo, no ser incluyentes de las diversidades. $Y$ quien no hable de feminismos es descartable por no estar en lo actual, al día.

Heteropatricarcal es otra de esas palabras posmo que resultan en una redundancia, lo heterosexual como norma obligatoria, es patriarcal por antonomasia, por lo tanto, casi no es necesario subrayarlo. Sin embargo, es una noción que suena bonito, suena chic y hay que usarlo por lo mismo. Se dice que es justamente para enfatizar el carácter heteronormativo del patriarcado, puede ser que así sea.

Por otro lado, las activistas y académicas de la descolonización en América Latina, durante la segunda década del siglo XXI, en varios textos se han volcado a la defensa de la descolonización o decolonización y lo que quieren descolonizar no son solamente los discursos sexistas, homofóbicos, neoliberales dominantes y demás, sino que quieren descolonizar, casi en primer término, el discurso feminista y pretenden "la desconstrucción de los feminismos hegemónicos occidentales" (Gómez y Lozano 2019: 94). Pasan del singular al plural con referencia al feminismo, sin orden ni concierto. Pero, sobre todo, lo que quieren es deshacerse del legado de los discursos universalistas que las ha llevado a reproducir el pensamiento feminista burgués del cual intentan despojarse. De acuerdo con las autoras de esta corriente, el feminismo latinoamericano se fundó sobre la herencia del colonialismo y el pensamiento eurocéntrico. Según ellas una

Revista Zona Franca- Centro de estudios interdisciplinario sobre las mujeres (CEIM)- Maestría poder y sociedad desde la problemática de género (MG), Rosario, Argentina. ISSN, 2545-6504 http://zonafranca.unr.edu.ar/index.php/ZonaFranca| Número 28 (2020). 
perspectiva descolonial busca explorar "los retos y posibilidades que enfrentan las jóvenes feministas latinoamericanas en la deconstrucción de los feminismos hegemónicos occidentales." (Gómez y Lozano 2019: 94). Si se habla de hegemonía quizá sería el feminismo y no los feminismos. Y esto de que el feminismo en la región latinoamericana y caribeña (que casi nunca es mencionada esta última) se fundó en el colonialismo y lo eurocéntrico (además de gringocéntrico) ni duda cabe. El pensamiento de la región ha abrevado de Europa y otros lugares, en muchos campos. Es un gran referente intelectual y político aún hoy en día, aunque no nos guste. Pero nada de eso tiene que ver con lo burgués. A menos que nos remontemos a los orígenes y nos demos cuenta de que ¡Olympe de Gouges era burguesa!

\section{Esencialismo, mujerismo y victimismo}

Asimismo, la lucha contra el llamado esencialismo y el mujerismo parece ser más virulenta que contra el propio machismo incluso desde el propio feminismo o pseudo-feminismo.

¿Igualdad o diferencia? Ambas, siempre ambas. Igualdad entre todos los seres humanos y diferencia entre cada todos. Igualdad de derechos entre hombres y mujeres, conservando diferencias. Ni siquiera se entiende porqué se ha presentado esta cuestión, como una disyuntiva. Es preciso que exista un equilibrio entre igualdad y diferencia entre los sexos/géneros, no es posible apostar por una igualdad sin contemplar la diferencia y viceversa. Me parece muy acertada la afirmación-interrogante de Deborah Cameron: “¿para que exista la igualdad todo el mundo ha de recibir el mismo trato? ¿O algunas clases de igualdad solo se alcanzan si no tratas a todo el mundo de forma idéntica?" (Cameron 2019: 63). Igualdad y diferencia, ya lo dijo muy bien hace tiempo Victoria Sendón en“¿Qué es el feminismo de la diferencia? (Una visión muy personal)".A trabajo igual, salario igual. Paternidad y maternidad responsables, de forma equitativa. Igualdad para desaparecer los techos de cristal. Igualdad de oportunidades en todo. Derechos a

Revista Zona Franca- Centro de estudios interdisciplinario sobre las mujeres (CEIM)- Maestría poder y sociedad desde la problemática de género (MG), Rosario, Argentina. ISSN, 2545-6504 http://zonafranca.unr.edu.ar/index.php/ZonaFranca| Número 28 (2020). 
padres y madres por igual, pero diferentes si la madre está lactando. Los mismos derechos a la salud, la educación, los trabajos. Pero no somos iguales, somos diferentes machos y hembras, hombres y mujeres. Por ejemplo, las personas transgénero y transexuales requieren derechos iguales, pero también con sus especificidades. Las mujeres requieren permisos y tiempos diferenciados para parir, amamantar, que los varones no requieren.

Hay un asunto, el de los géneros, bastante complejo todavía ¿cuántos géneros existen? ¿Tantos como individuos, es un asunto personal o social? Se habla de combatir el sexo y el género binarios. Me parece excelente. Como idea. Y por qué razón tantas lesbianas parecen hombres y tantos homosexuales quieren parecer mujeres, asemejan mujeres. Ambos en sus formas más estereotipadas, ambos reproduciendo a los sujetos performativos.

El esencialismo es algo que se inventó para tachar cualquier cuestión dentro del feminismo con la que no se está de acuerdo de esencialista. O sea, biologicista. Se utiliza de manera muy fácil y rápida constantemente para desacreditar alguna idea que haga referencia a las mujeres como género $y$, peor aún, a la mujer como concepto abstracto al considerar acertadamente que LA mujer no existe en el mundo concreto sensible. O sea, si se afirma que las mujeres son de determinada manera es ser esencialista puesto que se supone que nada que compartan las mujeres a no ser una esencia femenina. $Y$ no comparten nada porque cada mujer es diferente de la de al lado. Una rosada, una negra, una morena y el consabido largo etcétera. Pero, en realidad, las mujeres por distintas que sean entre sí comparten el hecho de ser mujeres y ser maltratadas como tales.

Algunas feministas han estado obsesionadas por décadas con el esencialismo, o sea piensan que cada vez que dicen que algo es femenino es ser esencialista, pues remite a los elementos fundamentales o "esencia" de las 
hembras de los seres humanos. Lo que hace que sean hembras, que no mujeres, pues remite a lo biológico.

El mujerismo, nuevamente, es un concepto para desacreditar de un plumazo algo que se expresa y con lo que no se está de acuerdo. Es decir, si se apoya a una mujer para un cargo público por el mero hecho de ser mujer es mujerismo. Pero esto es así si es que se trata de una mujer poco calificada y antifeminista. Sin embargo, hay que tener en cuenta que en los Estados Unidos surgió el concepto womanist desde la negritud para enfrentarse al concepto de feminismo que supuestamente detentaban las mujeres blancas. Fue la escritora Alice Walker quien acuñó el término en 1979 en un cuento titulado "Coming Apart" (Deshaciéndose). Así, lo que en un país representa la reivindicación de las mujeres negras frente a un feminismo llamado "hegemónico" por ser el que iniciaron mujeres blancas, en otro(s) representa la expresión reaccionaria del apoyo incondicional a las mujeres solo por ser mujeres.

El uso de la x, @, la e o la i para el plural niñis, por ejemplo, aparece como lo más incluyente que existe en el lenguaje escrito unos y hablado otros, pero pienso que es una falsa salida pues acabamos desapareciendo a las mujeres de forma parecida a como se hizo detrás de genérico masculino. Ahora es un genérico masculino y femenino pero con i en lugar de la o masculina. ¿De verdad cuesta mucho trabajo buscar genéricos neutros existentes (o crearlos) y/o repetir las palabras en masculino y femenino? Cuando escuchamos a algún orador u oradora hablando en público con lenguaje incluyente no forzado si no natural, por ejemplo, a Claudia Sheinbaum, a Hugo López-Gatell y a otros $u$ otras funcionarias del gobierno mexicano, resulta muy agradable y así podemos constatar que sí se puede hacer de otra manera más práctica y más incluyente que la i o la e: ejemplo, todes. Finalmente se desaparece a lo femenino (y lo masculino) de un zarpazo ¿es eso bueno, positivo? Podría serlo si viviéramos en una sociedad igualitaria, pero en vista de la gran diferencia jerárquica en detrimento de las mujeres lo conveniente es hacerlas visibles siempre que se pueda. Lo contrario es

Revista Zona Franca- Centro de estudios interdisciplinario sobre las mujeres (CEIM)- Maestría poder y sociedad desde la problemática de género (MG), Rosario, Argentina. ISSN, 2545-6504 http://zonafranca.unr.edu.ar/index.php/ZonaFranca| Número 28 (2020). 
una aberración. De la misma manera que las bibliografías que solo usan la inicial del nombre (aparte de ser poco claras) borran la presencia de las mujeres en las referencias y evitan saber el género de las personas citadas lo cual resulta ser un gran inconveniente, sobre todo desde el feminismo. Es imprescindible saber si los sujetos citados son hombres o mujeres y quién escribe determinado texto. Es tan importante porque en ocasiones se expresa una idea y es relevante saber si es un hombre o una mujer quien la suscribe.

El backlasho contraofensiva hacia el feminismo jes feroz!!!! Lo podemos constatar por todas partes en la vida real en su forma más extrema: los feminicidios. En la academia se viven todos los días los virulentos ataques de los varones en contra de las feministas que adquieren un cierto poder. No falta el insulto de feminazis o de feministas radicales. También en la cultura popular, por ejemplo, en el cine hollywoodense y en todos los demás, en donde se puede ver la revancha machista en sus múltiples y complejas formas. 'En los contenidos de las películas o en la representación de los personajes femeninos (con suma frecuencia jóvenes, bellos y quejumbrosos o bien maduras histéricas y malvadas).

Todas las personas débiles de este mundo han tendido siempre a la victimización. Las mujeres en tanto mujeres, la han manejado a diestra y siniestra. El feminismo ha tenido que estar muy alerta, buscar (y encontrar) todas las formas posibles para combatirla. Creo que ha salido bastante bien librado, en términos generales. Ahora bien, hay varios grupos de mujeres afrodescendientes, discapacitadas, indígenas, gordas, anoréxicas, de la llamada diversidad sexual, con sexualidades e identidades plurales, queer (o bien en tránsito entre un sexo o un género y otro -contra el binarismo, pero de uno a otra-) las intersexo, las sexoservidoras, la lista sería muy larga, pero a lo que voy es a que cada grupo se siente más discriminado, marginado, rechazado que cualquier otro. Cada uno ha sufrido mucho más que cualquier otro y lo hacen saber a los cuatro vientos siempre que pueden. Las salidas a esta cuestión también han estado ahí a la

\footnotetext{
` Ver el libro de Zeisler, 2017.
}

Revista Zona Franca- Centro de estudios interdisciplinario sobre las mujeres (CEIM)- Maestría poder y sociedad desde la problemática de género (MG), Rosario, Argentina. ISSN, 2545-6504 http://zonafranca.unr.edu.ar/index.php/ZonaFranca| Número 28 (2020). Página 530 
mano. El feminismo, creo, ha ahuyentado todo lo que ha podido al victimismo, lo mismo que el movimiento de la negritud en los Estados Unidos lo ha combatido y lo combate black is beautiful y hoy (2020) con un fascista en el poder, son desde luego víctimas de ese poder, pero no victimistas. Resisten, Black Lives Matter.

El victimismo utiliza el hecho real, concreto, existente en la vida social de ciertas personas o grupos que son sujetos víctimas de la opresión, discriminación y maltrato de otros grupos con poder suficiente como para hacerlo. El victimismo surge de víctimas reales de carne y hueso, no inventadas. No surge de la nada como parece algunas veces cuando se hace referencia a él. Y, desde luego, las protestas, gritos, llantos, de las víctimas de abusos sobre sus personas no significan victimismo, son víctimas: de maltrato, de burlas, de violencia física, de discriminación, de explotación y de todo lo sabido. Si se logra protestar frente a ello, no se trata de victimismo. No se hacen las víctimas, son víctimas. Las mujeres somos víctimas de una sociedad que nos oprime y la revuelta contra ello no es victimismo.

\section{Sobre acoso}

El piropo hacia las mujeres se debe considerar acoso sexual. Sobre todo por desconocidos en la calle. Si se da en el marco de una relación jerárquica puede ser considerado hostigamiento sexual. Por más que a algunas mujeres les parezca halagador y hasta encantador que les digan cosas en el ámbito público (así se sienten bonitas y atractivas), a otras nos parece una opinión no solicitada sobre nuestro cuerpo con frecuencia ofensiva, cuando no francamente repugnante. Aun cuando griten "iguapa!" es una impertinencia, es comentar nuestros cuerpos en momentos a menudo inoportunos y no deseados.

Otra cosa distinta es cuando se prodigan piropos entre amigos y amigas. Es otro espacio y ahí reinan diferentes reglas de convivencia. Si un amigo o colega piropea a una mujer hasta se agradece, siempre y cuando no sea ofensivo,

Revista Zona Franca- Centro de estudios interdisciplinario sobre las mujeres (CEIM)- Maestría poder y sociedad desde la problemática de género (MG), Rosario, Argentina. ISSN, 2545-6504 http://zonafranca.unr.edu.ar/index.php/ZonaFranca| Número 28 (2020). 
evidentemente. De la misma manera, un amigo o colega le puede agradar el piropo de una mujer cercana, y ambos pueden convertirse en acoso si se vuelven reiterativos, realmente no deseados, y a todas luces molestos.

El acoso sexual hacia las mujeres, en todas sus formas, es el ejercicio de un poder, el masculino, sobre las mujeres, es una agresión sexista ultrajante.

Por usos y costumbres se ha violado a las mujeres por siglos. Por usos y costumbres se vende a las mujeres y se las casa contra su voluntad. Por usos y costumbres se les practica la clitoridectomía. Por usos y costumbres se ha mantenido a las mujeres encargándose de las labores domésticas, el cuidado y la crianza. Que el piropo responda a usos y costumbres no quiere decir que sea algo siempre deseable o deseado por las mujeres. El piropo en México es generalmente soez. Sin duda, cuando las mujeres envejecen y el piropo desaparece, pueden aflorar las inseguridades de las mujeres pues piensan que ya no son atractivas... sin duda sucede, vivimos en una sociedad machista que lo permea todo.

El movimiento del \#Metoo no es ni puritano ni victimista, al contrario, surge en una sociedad que tiene mucho de puritana, la norteamericana, pero va justamente a contrapelo de ello y no son victimistas quienes levantan valientemente la voz. Ellas han sido víctimas de acoso y no se hacen pasar falsamente por víctimas, no son victimistas.

El acoso sexual es solo una manifestación de las grandes injusticias hacia las mujeres y es una práctica cotidiana que padecen millones en todo el mundo. Si en alguna ocasión se acusa a alguien sin merecerlo será una excepción y será injusto, de la misma manera que si alguna mujer golpea a su pareja masculina será una excepción. Tan excepción como que una mujer lance un piropo grosero e insultante a un hombre en la calle.

Revista Zona Franca- Centro de estudios interdisciplinario sobre las mujeres (CEIM)- Maestría poder y sociedad desde la problemática de género (MG), Rosario, Argentina. ISSN, 2545-6504 http://zonafranca.unr.edu.ar/index.php/ZonaFranca| Número 28 (2020). 
El movimiento \#Metoo ha contribuido a crear conciencia sobre la problemática del acoso y el hostigamiento sexual, y por ello ha sido más que benéfico.Ha visibilizado el acoso pues se tiende a normalizar, a pensar que está bien y que agradecidas deben de estar las mujeres porque los hombres las volteen a ver, les digan cosas sexuales, las toquen y demás, eso significa que son de buen ver, apetitosas, deseables y... calladitas, porque si no, no obtendrán el trabajo o lo que requieren del sujeto hostigador.

Este movimiento no es mujerista ni esencialista. Defender los derechos de las mujeres no es ser mujerista, denunciar el acoso sexual no es ser mujerista o esencialista, es ser feminista. Si la denuncia de cualquier abuso o discriminación en contra de las mujeres se considera mujerista, quizá entonces el feminismo lo es.

\section{Lo transgénero, lo transqueer, lo raro}

Hay tantos géneros como personas en el mundo, dice Laurie Penny (2020). La posición feminista contra el binarismo genérico es lo transqueer. Son las de ella y muchas otras como ella, muy valientes posiciones, muy vanguardistas, de búsqueda constante y perseverante, sin haber encontrado realmente la respuesta, o las respuestas, al mundo genérico/sexual binario asfixiantemente opresivo. Sin embargo, en este conflicto de identidad genérica, en esta disforia de género (mucho más frecuente y presente en los sujetos de lo que se piensa), a menudo, manifiestan sufrir más que cualquiera y, por supuesto, más que cualquier mujer cis.

Me parece importante la manera en que Laurie Penny trata la cuestión concreta de qué hacer con el binarismo de género desde una posición crítica (llámese queer, trans o simplemente feminista): "Cuestionar el género -ya sea que signifique estar a horcajadas sobre lo binario del género, cruzarlo o romper sus

Revista Zona Franca- Centro de estudios interdisciplinario sobre las mujeres (CEIM)- Maestría poder y sociedad desde la problemática de género (MG), Rosario, Argentina. ISSN, 2545-6504 http://zonafranca.unr.edu.ar/index.php/ZonaFranca| Número 28 (2020). 
supuestos dondequiera que te encuentres- es una parte esencial del feminismo que me ha sostenido..." (Penny,2020). vI

$\mathrm{Ni}$ duda cabe que las múltiples luchas de las personas trans contra su marginación, su discriminación, es más que legítima, es imperativa. Tanto como para organizar su movimiento de manera autónoma y gritar alto y fuerte lo que les pertenece, sus derechos, sean feministas o no. Por ello, no es pertinente que su movimiento esté inmerso, subsumido en el movimiento feminista de mujeres. Para eso se crearon las alianzas y hay que fortalecer los puentes, los vínculos políticos. Es preciso decir que las personas trans tienen mucha necesidad de protagonismo y hemos tenido la experiencia, una y otra vez, que cuando se encuentran, entremezcladas, con el movimiento feminista tienden a ponerse bajo los reflectores con mucha facilidad, a tomar casi por asalto el micrófono y a querer ir en la descubierta de las manifestaciones. Su legítimo interés por salir de la marginación (además -en ciertos casos- con un pasado de socialización como varones que les dio poder o de mujeres que no han querido serlo y salen con arrojo) las hace tomar la palabra en cuanto tienen la oportunidad y en subir al "estrado" cualquiera que este sea, a las primeras de cambio y si hay cámaras y luces qué mejor que mejor. Desde luego que la problemática trans es muy compleja y atravesada por la clase, la etnia, la edad se complica aún más. No es la misma condición la de una sexoservidora indígena o negra que la de una trans género urbana mestiza y con recursos económicos.

Hay que tener sumamente presente que el hecho de que una persona sea trans no la hace necesariamente feminista y, tal vez, la mayoría no lo son. Por lo tanto, cuando se habla de inclusión trans en el feminismo se crea un malentendido que se ha arrastrado ya por un tiempo. Cuando las mujeres se juntaron, se organizaron y se organizan en tanto feministas con una lucha colectiva común, lo más importante es que son mujeres y fueron socializadas como mujeres. Y si son

\footnotetext{
VI "Questioning gender — whether that means straddling the gender binary, crossing it, or breaking down its assumptions wherever you happen to stand - is an essential part of the feminism that has sustained me..." (Penny, 2020).
}

Revista Zona Franca- Centro de estudios interdisciplinario sobre las mujeres (CEIM)- Maestría poder y sociedad desde la problemática de género (MG), Rosario, Argentina. ISSN, 2545-6504 http://zonafranca.unr.edu.ar/index.php/ZonaFrancal Número 28 (2020). 
lesbianas, trans, bi o lo que sea es una cuestión que no tiene por qué pasar a un primer plano cuando del movimiento feminista se trata. Ahora bien, en su seno se deben organizar, si lo desean, en tanto lesbianas activistas y luchar por sus derechos como mujeres lesbianas, negras, indias, bi, o lo que sea pertinente. Pero lo primero es el feminismo, es el piso común, es la plataforma que las cobija, que nos cobija a todas, vengamos de donde vengamos. Porque la meta colectiva común es una condición de subordinación a otro género dominante que hace lo que quiere con ellas, hasta matarlas si se le antoja. En todo caso, lo que no debería de ser una consideración es la de que alguien por ser trans (género, sexual...), queer, lesbiana, gay, lo que sea menos cis, por ese solo hecho, es feminista. No importando que su actuar en el mundo no lo sea. Con ello voy a que lo de ser incluyente, per se, es un sinsentido. ¿Quién incluye a quién (se supone que en el feminismo) y por qué razón?

Lo queer, hoy en día, se nombra casi siempre como teoría queer. La inmensa mayoría de quienes escriben sobre el tema son varones. Lo irónico es a sus bastante limitados y repetitivos planteamientos los llamen pomposamente teoría. De hecho, ya con eso, muestran una falta de humildad teórica y política evidente. Quizá han pensado en crear una teoría queer, pero lo que es hasta el presente, no hay tal.

Las palabras mágicas para todo lo anterior son, entonces, inclusión, diversidad y género. En función incluso de esos tres conceptos es que se articulan políticas públicas en diversas instancias, incluida la academia. Nótese, en primera instancia, que las mujeres desaparecieron, claro, como por arte de magia.

Hay mujeres trans, con diversas cargas políticas detrás, que han sido utilizadas (o lo hacen por motu propio) por las feministas, en particular dentro de la academia, pero no solamente. Al feminismo siempre se lo ha tachado de victimista, cuando ha convenido para atacarlo, desarticularlo, despreciarlo. Es muy común, pero no se critica a las personas trans de victimistas, por hacerse más

Revista Zona Franca- Centro de estudios interdisciplinario sobre las mujeres (CEIM)- Maestría poder y sociedad desde la problemática de género (MG), Rosario, Argentina. ISSN, 2545-6504 http://zonafranca.unr.edu.ar/index.php/ZonaFranca| Número 28 (2020). 
víctimas que cualquiera y, sobre todo, que cualquier mujer. Nos hacen saber que ellos, ellas con su doble, triple o más opresiones son quienes sufren de verdad por el patriarcado no así las mujeres cis.

Muchas feministas jóvenes dan por supuesto que existe algo que es el mainstream feminism o feminismo hegemónico. Ese es el blanco de las quejas de personas que se viven profundamente marginalizadas por la sociedad y por este feminismo dominante. Así, tenemos a lesbianas, lesbianas negras y lesbianas negras discapacitadas como June Eric-Udorie. También encontramos las mujeres negras transgénero como Gabriella Bellot. VII Esta autora que como muchas mujeres trans ha sufrido más que cualquiera o tanto como cualquier mujer $\mathrm{y}$, sin embargo, se decepciona terriblemente y se siente ofendida porque Chimamanda Ngozi Adichie expresó que las mujeres trans no son mujeres como las que han nacido y han sido socializadas como mujeres. No tengo ninguna duda de que personas trans han tenido una vida difícil en virtud, justamente, de las cuestiones de identidad genérica. Tampoco dudo que en muchos casos se lo han pasado más mal que montones de mujeres. Pero es por todo ello, por las dificultades del tránsito de identidad, por el trato que reciben, por un sin fin de problemáticas que son mujeres diferentes con una problemática específica y no individual sino a menudo compartida como grupo social.

Ahora bien, se entiende claramente que las mujeres transexuales quieran pertenecer al grupo mujeres, quieren dejar de ser varones y ser hembras y mujeres. Requieren ser aceptadas en ese grupo de manera "normal". Eso ha sido más que difícil porque no siempre lo logran. Y precisamente por esto su lucha feminista, sus luchas deben ser y son distintas porque no necesariamente comparten la misma condición genérica que las cis $u$ otras mujeres de la diversidad sexual. Es un hecho que nacemos con sexo. Es un hecho que se nos socializa en función de ese sexo. Aun tratándose de sujetos intersexuales pues no son socializados como tales (y ese hecho, en sí, es un grave problema). Si se

VII Ver su capítulo "Borderlands" en Eric-Udorie 2018: 47-60.

Revista Zona Franca- Centro de estudios interdisciplinario sobre las mujeres (CEIM)- Maestría poder y sociedad desde la problemática de género (MG), Rosario, Argentina. ISSN, 2545-6504 http://zonafranca.unr.edu.ar/index.php/ZonaFranca| Número 28 (2020). Página 536 
acepta que el movimiento feminista es plural, que hay posiciones divergentes e incluso encontradas, ¿por qué los furiosos ataques a las disidencias frente a los sujetos trans? Por qué la decisión de algunas feministas de integrar su presencia en el seno del movimiento -por el mero hecho de que eligieron ser mujeres- sin que haya un consenso. Si ellas deciden ser mujeres, actuar como mujeres e incluso llevar a cabo transformaciones químicas y quirúrgicas están en todo su derecho. Pero me pregunto si esa decisión de ser mujeres, utilizando toda la parafernalia de la feminidad estereotipada dentro del patriarcado y recogiendo de la basura lo que las feministas han tirado por opresivo y degradante, como decía Luis González de Alba (lo cito de memoria), me pregunto si eso representa una posición significativa para el pensamiento y la acción feministas.

Por otro lado, la escritora J.K. Rowling -relevante, diría yo, que esconda su nombre femenino Joanne detrás de las iniciales J.K.) fué acusada de transfóbica por hacer las siguientes aseveraciones "...borrar el concepto de sexo le quita a muchas personas la capacidad de hablar de sus vidas de manera significativa." [...] "Si el sexo no es real no hay una atracción de personas del mismo sexo. Si el

sexo no es real, la realidad que viven las mujeres en todo el mundo, se borra." $\mathrm{VIII} Y$ esto lo dijo, al parecer, en relación con el hecho de haber afirmado que las personas que tienen la menstruación deberían designarse como mujeres. Quizá habría que haber dicho con la posibilidad de tenerla, pues las niñas y las viejas no la tienen y son mujeres. Estoy de acuerdo con Rowling que lo trans, así como el género en muchos contextos, borra a las mujeres, borra las experiencias de las mujeres "reales".

\section{Pornografía y sexoservicio}

VIII Ver en inglés: https://variety.com/2020/film/news/eddie-redmayne-jk-rowling-antitrans-tweets-harry-potter-fantastic-beasts-1234630226/ consultada 10 junio 2020. O ver La Jornada. La Jornada de en Medio, México, 10 junio 2020, p. 7ạ.

Revista Zona Franca- Centro de estudios interdisciplinario sobre las mujeres (CEIM)- Maestría poder y sociedad desde la problemática de género (MG), Rosario, Argentina. ISSN, 2545-6504 http://zonafranca.unr.edu.ar/index.php/ZonaFrancal Número 28 (2020). 
No se puede ser abolicionista frente a la pornografía o la prostitución. Eso, sin duda representa tirar al bebé junto con el agua de la tina. Es probablemente cierto que la pornografía comercial es una "incitación a la violencia y a los abusos sexuales" (Cameron 2019:112), pero se coloca la dualidad placer frente al peligro y es quizá esa una forma maniquea de abordar la problemática. La pornografía puede existir sin que sea degradante para las mujeres, sexista, racista o etaria. Es como si se dijera que porque el sexo heterosexual, pero también el homosexual, es fundamentalmente orquestado para placer masculino o para placer del sujeto dominante en la relación, en virtud de ello habría que abolir el sexo. Lo mismo en cuanto a la prostitución. El sexoservicio es denigrante, abyecto, va en detrimento de quien vende su cuerpo. Pero no se resuelve prohibiendo que se venda el cuerpo, quizá la solución de prohibir la compra pone el peso en el lado de los hombres y no de las mujeres (sin olvidar hombres que venden y mujeres que compran, pero son minoría). ¿Es la salida a este problema simplemente la abolición vía prohibición? Si para miles de mujeres esa es la salida al hambre y la miseria, el problema no se soluciona con la abolición de la prostitución sino con cambios socio-políticos y económicos estructurales. Ambas son problemáticas bastante complejas que no se resuelven con el sí o el no a su existencia y persistencia en abstracto.

\section{De metodología y mitología}

En Debates en torno a una metodología feminista escribí sobre la existencia de un método de análisis y unas técnicas específicas de la investigación feminista. Cuando alguien usa la palabra feminismo se puede referir a varias cosas entre ellas dice Deborah Cameron (2019:11) en su reciente libro: "El feminismo como marco intelectual: lo que la filósofa Nancy Hartsock describió como 'un modo de análisis [...] una manera de formular preguntas y de buscar respuestas'."

El mito de la objetividad ha recorrido todas y cada una de las disciplinas y las ciencias sobre todo desde el positivismo hasta nuestros días.

Revista Zona Franca- Centro de estudios interdisciplinario sobre las mujeres (CEIM)- Maestría poder y sociedad desde la problemática de género (MG), Rosario, Argentina. ISSN, 2545-6504 http://zonafranca.unr.edu.ar/index.php/ZonaFranca| Número 28 (2020). 
En diversos lugares se ha expresado que el feminismo bueno no ese académico, sino el feminismo popular, el de los pueblos originarios, ese es el importante. O como lo afirma el uruguayo Raúl Zibechi, "movimiento de mujeres, movimiento feminista, pero no el feminismo académico sino el feminismo popular [...] un feminismo que es otra cosa de lo que conocimos desde los 80 en América Latina. Es la emergencia de los pueblos originarios, es el feminismo popular, plebeyo, indígena y radical, anticapitalista." (2020). El autor parece ignorar que en la década de los 80 dominó en algunos lugares (México entre ellos) el feminismo popular y que hoy, sin alejarse de la academia, también hay feminismo popular y comunitario. Por otro lado, también cree que el feminismo renace en los 80 y que el radical surge con la emergencia de los pueblos originarios, desconoce (como mucha otra gente) que feminismo radical hubo en el mundo desde mucho antes. En la década de 1970 existió un feminismo radical claramente identificable en ciertas partes de Nuestra América, distinto a lo que se denominaba feminismo radical en los Estados Unidos que se refería al feminismo lésbico.

En el Manifiesto del 99\% reclaman un "universalismo" como si fuera una cuestión novedosa cuando el feminismo de la segunda ola siempre fue internacionalista, más no universalista. Si por universalismo se entiende la creencia en una verdad única inamovible, objetiva, mundial y eterna, el feminismo nunca ha sido universalista. Y, sin embargo, se lo ha criticado hasta el cansancio incluidas Nancy Gómez y María Lozano quienes critican y afirman que hay que deshacerse del discurso universalista de la $2^{2}$ ola $(2019: 94,95,97)$. O se tacha, asimismo, de universalista al neofeminismo en el texto de Almudena Cabezas (2014) y en tantos otros. Varias de las cuestiones que se propugnan en el Manifiesto del 99\%no son para nada nuevas. Un feminismo anticapitalista y antimperialista, desde los 70's e incluso antes ha habido ese feminismo. Desde que surgió el de la segunda ola se rechazó el reduccionismo de la izquierda, del marxismo, en la medida en que pensaban que lo primero y más importante era la lucha de clases y luego ya vendría lo demás. Cuando ese feminismo surgió se

Revista Zona Franca- Centro de estudios interdisciplinario sobre las mujeres (CEIM)- Maestría poder y sociedad desde la problemática de género (MG), Rosario, Argentina. ISSN, 2545-6504 http://zonafranca.unr.edu.ar/index.php/ZonaFranca| Número 28 (2020). 
enfrentó de inmediato a dicho presupuesto de la izquierda. $Y$, a pesar de que se piensa que la interseccionalidad surgió a finales de los 80 , ya antes se hacía referencia a las diversas desigualdades por sexo (género), raza (racialización), preferencia sexual (diversidad sexual), habilidades corporales, edad, clase, etnia y no se privilegiaba a ninguna sino que debían considerarse todas. No había una contradicción principal, como en el marxismo, sino que había numerosas contradicciones todas igualmente importantes.

En el Manifiesto para el $99 \%$ se dice que no es una utopía lo que plantean, pero pienso que cuando hablan de lo que desean, lo que quieren y lo que proponen es pura utopía, yo la suscribo al $99 \%$, no tengo nada en contra delas utopías, ellas han movido al mundo y lo siguen haciendo. (Arruzza, 2019). Sin embargo, se proponen trazar el camino para lograr la sociedad no capitalista, justa, igualitaria, antirracista, anti-patriarcal, pero el camino no se ve claramente trazado. Una estrategia que se menciona es la coordinación entre diferentes movimientos, lo cual tampoco es algo novedoso pues hace referencia a las famosas alianzas entre grupos y movimientos feministas y de mujeres. Se trata de una sumatoria de causas justas, de luchas de clases, ambientalistas y antirracistas. Más que nada para un cambio social y por ello se requiere la coordinación de movimientos. En el Manifiesto dicen que el feminista no puede ser separatista. No veo la razón. Se puede tratar de un movimiento autónomo de mujeres que se coordina con otros movimientos. En los 70 s se hablaba de autonomía del movimiento, hoy se dice separatismo. Queremos, desde luego, un sistema de salud pública para todo el mundo (aunque esto lo han tenido y lo tienen países capitalistas y hasta neoliberales). Todo ello representa una nueva ola del feminismo, y coincido en ello, pero nunca se dice si es la tercera, la cuarta o cuál. Sus posiciones son radicales en la medida en que van en contra de la meritocracia del feminismo liberal, su ganar espacios y su romper el techo de cristal.

\section{Rabia, enojo, cólera e ironía subversiva}

Revista Zona Franca- Centro de estudios interdisciplinario sobre las mujeres (CEIM)- Maestría poder y sociedad desde la problemática de género (MG), Rosario, Argentina. ISSN, 2545-6504 http://zonafranca.unr.edu.ar/index.php/ZonaFranca| Número 28 (2020).

Página 540 
La enorme cólera que se ha visto en las calles de la Ciudad de México a partir de 2019, pero no solamente ahí sino que es algo que ha aflorado en diversas partes del país y del mundo, es pura y simplemente una manifestación más que legítima de enojo, de indignación, ante tanta brutalidad en contra de las mujeres, por donde se mire, por doquier. Las mujeres jóvenes, el nuevo movimiento feminista, han dicho basta, han gritado y seguirán gritando ¡basta! La enorme ventaja, frente al neofeminismo de los 70,es que hoy en día no son cincuenta no son cien sino miles y miles de gargantas que gritan al unísono: ni una más (ni una muerte más) o bien ni una menos (ni una mujer viva menos). Una frase alude a la muerte, la otra a la vida, no deja de ser significativa la diferencia en las consignas que pretenden decir lo mismo, pero lo expresan de manera inversa. Es probable que tenga que ver con el arraigo cultural de cada una.

La cólera, ya hablaba de ello la mismísima Virginia Woolf en Una habitación propia, es fundamental para las mujeres en rebeldía. Las mujeres no conformes con lo que les ha tocado vivir, a disgusto con ello, expresan con cólera y su insatisfacción de muy diversas maneras. Puede ser en la calle, en la casa, en la literatura, en las artes visuales.

La cólera puede significar el inicio de la resistencia, de la lucha contra los poderes que nos atropellan. En la vida diaria, cada vez que una mujer se enoja frente a algún acontecimiento cotidiano, con frecuencia sale la voz masculina que dice-ordena "no se enoje, señora". La cólera es un sentimiento útil para los y las de abajo. La resignación, que es un sentimiento cristiano, (que no la resiliencia), en cambio, lleva a aceptar la adversidad, no hacerle frente, no luchar.

Y es precisamente la "indignación, el cansancio y el hartazgo" lo que se ha convertido en el capital político del feminismo del siglo XXI, de acuerdo con Nuria (Varela, 2019: 148). Y es muy importante cómo señala, ahora sí, las claras diferencias entre este feminismo que ella llama de la cuarta ola y los anteriores. A lo que ella enumera y explica como la importancia del ciberactivismo, con toda su

Revista Zona Franca- Centro de estudios interdisciplinario sobre las mujeres (CEIM)- Maestría poder y sociedad desde la problemática de género (MG), Rosario, Argentina. ISSN, 2545-6504 http://zonafranca.unr.edu.ar/index.php/ZonaFranca| Número 28 (2020). 
enorme complejidad y potencial, yo añadiría la cultura pop y lo multimedia como estrategias fundamentales de manifestación del feminismo actual. IX (Gómez y Lozano, 2019: 100). Este feminismo empezó a fraguarse en el 2010 por lo que lleva más o menos una década.

La ironía es un arma fundamental tanto de las mujeres, en general, como de las feministas en específico. Esta se utiliza en la vida cotidiana, en la literatura, y en el activismo, desde luego. En la vida cotidiana es una de las formas más socorridas de enfrentar el machismo en las familias o en los medios laborales.

Se ha estudiado bastante ya la estrategia irónica que utilizaron tanto Virginia Woolf como Rosario Castellanos en su obra. ${ }^{X}$

La ironía puede ser una forma soslayada de enfrentar la agresión machista. El caso es que las mujeres feministas la han usado y la usan constantemente. Resulta una forma muy elegante de enfrentar la discriminación.

Donna Haraway, en su texto Manifiesto Cyborg propuso reivindicar la ironía y escribió "La ironía se ocupa de las contradicciones que, incluso dialécticamente, no dan lugar a totalidades mayores, y que surgen de la tensión inherente a mantener juntas cosas incompatibles, consideradas necesarias y verdaderas. La ironía trata del humor y de la seriedad. Es también una estrategia retórica y un método político para el que yo pido más respeto dentro del feminismo socialista." (Haraway 1991:1).

\section{Diversidad}

Respeto a la diversidad (¿las diversidades?). A la diversidad sexual en primer lugar, entendible, necesaria, imprescindible... vivimos en una sociedad dominada por la heterosexualidad obligatoria, ya lo explicó certeramente Adrienne

\footnotetext{
IX Para profundizar en el papel de la cultura pop como estrategia feminista ver Gómez y Lozano. $\times$ Ver, por ejemplo, Orlando de Virginia Woolf. Para un estudio sobre la ironía en R. Castellanos ver Megged, 1984.
}

Revista Zona Franca- Centro de estudios interdisciplinario sobre las mujeres (CEIM)- Maestría poder y sociedad desde la problemática de género (MG), Rosario, Argentina. ISSN, 2545-6504 http://zonafranca.unr.edu.ar/index.php/ZonaFranca| Número 28 (2020). 
Rich en "Compulsory Heterosexuality and Lesbian Existence" (1980). Surge por la imperiosa necesidad de que el lesbianismo se hiciera visible y respetable, que no tolerable. No se trata de tolerarlo ni mucho menos. Tolerar es soportar, respetar es tomar en cuenta a lo otro y considerarlo importante. De ahí otras minorías como bisexuales, trans de todo tipo, discapacitadas, desde luego minorías étnicas y racializadas, ancianidad, todos los grupos que podrían ser diversos de la norma dominante son considerados "diversidad", o bien personas diversas. Esta última noción es bastante incómoda. "La defensa de las personas diversas" ¿Qué no somos todas y cada una de las personas diferentes de la de junto? ¿Quiénes serían, entonces, las personas diversas? La noción de diversidad sexual creo que es afortunada en la medida en que denota lo diferente frente a la norma heterosexual establecida. De ahí se ha querido estirar la cuerda para que quepan más cosas, más desigualdades sociales, pero en realidad son tantas que, por supuesto no caben. Diversidad genérica, étnica, ¿y la diversidad pálida 0 caucásica minoritaria en países mestizos o en diversas partes del mundo? Habría entonces que considerar diversidad oprimida 0 marginada, es necesario especificar. Finalmente, si lo estiramos un poco, lo mismo sucede con diversidad sexual. Mi sexualidad lésbica es diversa de la heterosexual que domina, pero mi sexualidad heterosexual difiere, probablemente de la tuya, también heterosexual. Cada sexualidad es distinta, diversa de las otras. A mí me gustan unas cosas, yo tengo unas fantasías perversas bien diversas y distintas de las tuyas y así. Pero se ha dado hoy en hablar de las personas diversas, sobre todo para no dejar nunca de ser incluyentes.

Pero antes de las diversidades se hablaba ya de la enorme diversidad en el seno del movimiento feminista (como si se descubriera el agua tibia) y justo por culpa (aunque no se dice) de la diversidad es que no se ha podido unificar. Es "altamente diversificado y difícil de cohesionar," afirma Almudena Cabezas (2014:1). A su vez cita a Sonia Brito quien afirma que: "En el reino de la diversidad

Revista Zona Franca- Centro de estudios interdisciplinario sobre las mujeres (CEIM)- Maestría poder y sociedad desde la problemática de género (MG), Rosario, Argentina. ISSN, 2545-6504 http://zonafranca.unr.edu.ar/index.php/ZonaFranca| Número 28 (2020). 
sería un error considerar la existencia de un movimiento de mujeres unificado y homogéneo" (2014:1). Es que nunca lo ha sido ni ha pretendido serlo.

Por lo tanto, paradójicamente, se quiere enfatizar y respetar la diversidad que, al mismo tiempo, impide la unificación.

\section{Lo novedoso y lo perverso}

Una de las perversiones peores que ha padecido el feminismo ha sido la posmodernidad. Me refiero a la supuesta teoría posmoderna con su falsa complejidad e ininteligibilidad, con un barroquismo lingüístico totalmente innecesario que, finalmente, lo que esconde es una falta de propuestas teóricas y políticas nuevas.

Con demasiada frecuencia se expresan ideas como si fueran la gran novedad y, en realidad, con el mismo nombre o con otro son ya bastante viejas dentro del pensamiento feminista.

Que las mujeres no conformamos un grupo homogéneo. Se ha dicho desde hace tiempo, por lo menos en los 70 ya se decía. Que en ese grupo hay negras, indígenas (de las blancas ni se habla), o sea se especifica la racialización y la etnia de algunas. Las blancas no pertenecen a etnia alguna. Luego se mencionan las clases sociales en las que aparecen las campesinas (las obreras con frecuencia no están), trabajadoras sexuales y, en estas diversidades meten a las discapacitadas, las lesbianas y las trans. Evidentemente no está toda la diversidad de mujeres sino solamente las que se consideran más vulnerables, (aun así faltarían muchas) pues hay más clasificaciones de mujeres en el mundo. Y se habla a menudo de feministas y lesbianas. Lo cual me parece el colmo del absurdo, hay feministas lesbianas y lesbianas no feministas entonces por qué esa división sin sentido. Hay feministas activistas -entre ellas las activistas lesbianas-, las activistas a favor de la igualdad o bien de la diferencia, activistas ecologistas y la lista puede ser larguísima.

Revista Zona Franca- Centro de estudios interdisciplinario sobre las mujeres (CEIM)- Maestría poder y sociedad desde la problemática de género (MG), Rosario, Argentina. ISSN, 2545-6504 http://zonafranca.unr.edu.ar/index.php/ZonaFrancal Número 28 (2020). 
Pienso que la primera exigencia que deben de hacer las feministas lesbianas no es hacia las feministas hetero sino hacia sistema capitalista patriarcal para que sean tomadas en cuenta e incluidas en los planes y programas de toda índole, en las políticas públicas, la educación, la salud, los proyectos de todo tipo, gubernamentales y no gubernamentales. ¿Por qué pedirlo a las mujeres organizadas, en movimiento, y muchas de ellas autónomas? Quieren, piden, exigen un feminismo inclusivo ¿a quién se lo piden? ¿Quién tiene el poder de decisión sobre las personas, los grupos, colectivos y colectivas para que puedan 0 no formar parte del movimiento feminista, para incluirlas?

Una de las grandes novedades, junto con las ya mencionadas, dentro del movimiento feminista es el uso de la tecnología, las estrategias utilizadas con las redes sociales y todo lo que aporta el mundo digital e Internet que es algo fundamental en estos días $y$, desde luego, algo novedoso que contribuye a considerar la existencia de una nueva ola feminista, la tercera.

Como feministas queremos cambiarlo todo y el todo es enorme. La gran revolución radical anti-patriarcal, anticapitalista, antirracista, antimperialista, contra las iglesias, los ejércitos, las fronteras, la medicina privada, las farmacéuticas voraces que no curan sino que enferman, la familia patriarcal.

En los setentas se hablaba de la autonomía del movimiento feminista, hoy en día se habla de separatismo. Ha cambiado la palabra, el concepto es el mismo.

Resulta muy interesante que casi todas las que escriben sobre las pautas que debería de seguir el movimiento feminista para ganar terreno, para lograr avanzar contra el patriarcado, mencionan la cuestión de las alianzas. "articular políticas de alianzas con otros sectores sociales" lo llama Rosa Cobo y "para ello es necesario desarrollar una cultura política de pactos" (Cobo 2011: 227). En efecto, esta es una tarea a la que el movimiento feminista se ha abocado desde hace muchísimo tiempo, tampoco es algo nuevo, aunque, la verdad sea dicha no ha sido muy exitoso en el campo de las alianzas. Se han dado, desde luego, pero

Revista Zona Franca- Centro de estudios interdisciplinario sobre las mujeres (CEIM)- Maestría poder y sociedad desde la problemática de género (MG), Rosario, Argentina. ISSN, 2545-6504 http://zonafranca.unr.edu.ar/index.php/ZonaFranca| Número 28 (2020). 
no es una cuestión que haya sido particularmente fecunda. Habría que pensar la razón, pero es probable que las ideas y las concepciones políticas de cada grupo no permitan fácilmente la vinculación con grupos que no son particularmente afines.

El libro de Andi Zeisler, We Were Feminists Once... (2016) es sobre lo perverso en lo que han convertido al feminismo las corporaciones transnacionales. Se trata de la cooptación, la banalización y la mercadotecnia utilizando al feminismo lo cual inició hace ya un par de décadas, pero va en aumento. La mercantilización del feminismo ha venido llegando poco a poco y es parte del backlash, de la revancha del patriarcado frente a la diseminación del feminismo. Los medios y la cultura popular es el campo en donde Zeisler piensa que se encuentran los mecanismos para el cambio de mentalidades.

Lo que hacen los medios y las corporaciones con el feminismo es pura y simplemente cooptarlo para desmantelarlo, entibiarlo lo más posible, desvirtuarlo en cuanto pueden. No hay duda de que su entibiamiento acabará dominando de manera voraz como toda mercadotecnia y así las ideas y los compromisos junto con la radicalidad quedaran en el trastero de la historia.

Hoy en día (2020) hay una gran coincidencia en que el nuevo feminismo de la $3^{\underline{a}}$ ola, que es radical si se quiere, es además ecofeminista o ambientalista, es antirracista, anticapitalista, antipatriarcal y como estrategias utilizala calle, los medios (las nuevas Tecnologías de la Información y la Comunicación o TICs), es ciberfeminista por excelencia y es interseccional, aunque esto no tenga más que la etiqueta de nuevo pues se dio desde la $2^{\underline{a}}$ ola. El feminismo de hoy, ante todo de mujeres jóvenes, es muchas cosas, como vemos, y quizá, algún día se le considerará "hegemónico".

\section{Bibliografía}

Revista Zona Franca- Centro de estudios interdisciplinario sobre las mujeres (CEIM)- Maestría poder y sociedad desde la problemática de género (MG), Rosario, Argentina. ISSN, 2545-6504 http://zonafranca.unr.edu.ar/index.php/ZonaFranca| Número 28 (2020). 
AGUILAR, Pilar (2020). "Aliadas del patriarcado", https://tribunafeminista.elplural.com/2018/01/aliadas-del-patriarcado/ consultada 4 junio 2020.

ARRUZZA, Cinzia; Tithi, BHATTACHARYA y Nancy FRASER (2019). Feminism for the 99\%, Londres, Verso.

BARNETT, Avrom. (1921) Foudations of Feminism [A Critique], Nueva York, Robert McBride \& Co.

BARROSO, José María. (2014). "Feminismo decolonial: una ruptura con la visión hegemónica eurocéntrica, racista y burguesa. Entrevista con Yuderkys Espinosa Miñoso", Iberoamérica Social: revista-red de estudios sociales (III), pp. 22 - 33. Recuperado de http://iberoamericasocial.com/feminismo-decolonial-unaruptura-con-la-vision-hegemonica-eurocentrica-racista-yburguesa

Etiquetado como Descolonización, Género, Pensamiento Político, Sociedad

CABEZAS GONZÁLEZ, Almudena (2014). "Anotaciones sobre el tejido feminista latinoamericano: más allá de las genealogías", Contextualizaciones Latinoamericanas, Año $\quad 6, \quad$ número $11, \quad$ juliodiciembre.www.contextualizacioneslatinoamericanas.com.mx

https://www.academia.edu/8652383/Anotaciones sobre el tejido feminista I atinoamericano más allá de las genealog\%C3\%ADas?email work card=viewpaper Consultada 6 mayo 2020

CAMERON, Deborah (2019). Feminismo, Madrid, Alianza Editorial.

COBO, Rosa (2011). Hacia una nueva política sexual. Las mujeres ante la reacción patriarcal, Madrid, Los libros de la Catarata.

DE GOUGES, Olympe (1791). Déclaration des droits de la femme et de la citoyenne.

https://fr.wikisource.org/wiki/D\%C3\%A9claration des droits de la femme et de la citoyenne

ERIC-UDORIE, June (ed.). (2018). Can We All Be Feminists? Nueva York, Penguin Books.

Revista Zona Franca- Centro de estudios interdisciplinario sobre las mujeres (CEIM)- Maestría poder y sociedad desde la problemática de género (MG), Rosario, Argentina. ISSN, 2545-6504 http://zonafranca.unr.edu.ar/index.php/ZonaFrancal Número 28 (2020). 
FOLLEGATI MONTENEGRO, Luna (2018). "E feminismo se ha vuelto una necesidad: movimiento estudiantil y organización feminista (2000-2017)", Revista Anales, $7^{\text {a }}$ serie, № 14 . pdf

GAMBA, Susana (2020). "Feminismo: historia y corrientes", Mujeres en red. El periódico feminista, http://www.mujeresenred.net/spip.php?article1397 consultada 15 junio. Feminismo_historia_y_corrientes.pdf

GARCÍA ORASMAS, María José (2019).“Feminismos contemporáneos: inclusión total y otros pendientes. Entrevista con Nancy Fraser", La Jornada Semanal, № 1261, México, 8 mayo, pp. 8-10.

GÓMEZ, Nancy y María LOZANO (2019). "La descolonización del discurso feminista latinoamericano en (e)stereotipas", Journal of International Women's Studies, Vol. 20, № 6, junio, pp. 94-110.

HARAWAY, Donna (1991). Manifiesto Cyborg. En https://dpya.org/wiki/images/8/8e/Manifiesto ciborg.pdf

LAU JAIVEN, Ana (2014). "La Unión Nacional de Mujeres Mexicanas entre el comunismo y el feminismo: una difícil relación", La Ventana. Revista de Estudios de Género, Vol. V, núm. 40, pp.165-185.

MEGGED, Nahum. (1984). "Rosario Castellanos: un largo camino a la ironía", Jornadas, México, El Colegio de México, https://www.jstor.org/stable/j.ctv6mtcn5.5? refreqid=excelsior\%3A757f20831fd09e3 ca9fec2dae9eb4ad6\&seq=1\#metadata info tab contents consultada 27 agosto 2020

ORTIZ AÑORVE, Zenaldo (2020). Feminismo en México, Capítulo II, https://www.academia.edu/14670942/42 CAP\%C3\%8DTULO II FEMINISMO EN M\%C3\%89XICO consultada 24 agosto 2020.

PENNY, Laurie (2020). "How To Be A Gender queer Feminist", https://www.buzzfeednews.com/article/lauriepenny/how-to-be-a-genderqueer-

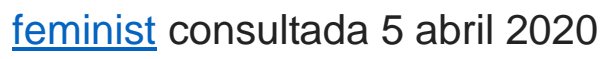

Revista Zona Franca- Centro de estudios interdisciplinario sobre las mujeres (CEIM)- Maestría poder y sociedad desde la problemática de género (MG), Rosario, Argentina. ISSN, 2545-6504 http://zonafranca.unr.edu.ar/index.php/ZonaFrancal Número 28 (2020). 
RICH, Adrienne (1980). "Compulsory Heterosexuality and Lesbian Existence". Signs: Journal of Women in Culture and Society. 5, 4, verano, pp. 631660.

RODRÍGUEZ MAGDA, Rosa Maํ (2019). La mujer molesta. Feminismos postgénero y transidentidad sexual, Madrid, editorial Ménades.

RYAN, Frances (2018). "No disabled access" in June Eric-Udorie (ed.). Can We All Be Feminists?, Nueva York, Penguin Books.

http://www.scielo.org.mx/scielo.php?script=sci arttext\&pid=S140594362014000200007 Consultada 27 mayo 2020.

SENDÓN DE LEÓN, Victoria (2000). "Qué es el feminismo de la diferencia? (Una visión muy personal)

https://xenero.webs.uvigo.es/profesorado/purificacion mayobre/feminismo

VARELA, Nuria (2019). Feminismo 4.0 La cuarta ola, Barcelona, Penguin Random House.

ZEISLER, Andi (2016). We Were Feminists Once: From Riot Grrrl to Covergirl, the Buying and Selling of a Political Movement, Nueva York, Public Affairs.

Revista Zona Franca- Centro de estudios interdisciplinario sobre las mujeres (CEIM)- Maestría poder y sociedad desde la problemática de género (MG), Rosario, Argentina. ISSN, 2545-6504 http://zonafranca.unr.edu.ar/index.php/ZonaFrancal Número 28 (2020). 